\title{
Factors Influencing Optimal Hospital Design: A Comparative Study between Thai and Norwegian Public Hospitals
}

\author{
Supuck Prugsiganont, Tanut Waroonkun* \\ Faculty of Architecture, Chiang Mai University, Thailand \\ Received March 16, 2021; Revised May 7, 2021; Accepted May 28, 2021
}

\section{Cite This Paper in the following Citation Styles}

(a): [1] Supuck Prugsiganont, Tanut Waroonkun, "Factors Influencing Optimal Hospital Design: A Comparative Study between Thai and Norwegian Public Hospitals, "Civil Engineering and Architecture, Vol. 9, No. 4, pp. 976 - $991,2021$. DOI: $10.13189 /$ cea.2021.090402.

(b): Supuck Prugsiganont, Tanut Waroonkun (2021). Factors Influencing Optimal Hospital Design: A Comparative Study between Thai and Norwegian Public Hospitals. Civil Engineering and Architecture, 9(4), 976 - 991. DOI: 10.13189/cea.2021.090402.

Copyright $\subseteq 2021$ by authors, all rights reserved. Authors agree that this article remains permanently open access under the terms of the Creative Commons Attribution License 4.0 International License

\begin{abstract}
This paper aims to determine the factors that influence the design process for public hospitals. The paper intends to provide knowledge regarding the hospital planning and design process from the perspective of policy makers, facilities managers, hospital planners and hospital designers. This study is a qualitative study, where twelve participants from Thai and Norwegian hospitals were interviewed. Respondents included hospital project directors $(n=3)$, hospital planners/designers $(n=5)$, and facilities managers $(n=4)$. Interviews were transcribed and analysed using thematic and content analysis. Four main themes were identified from the analysis: (1) organization of the healthcare system (2) hospital management system (3) work systems in the healthcare organization (4) hospital design process. Comparisons of results were made between Thailand (a developing country that strives to provide sufficient healthcare services) and Norway (a developed Nordic country that provides efficient public healthcare services). The main finding of this study indicates the critical importance of user involvement in the hospital design process in both countries. The involvement of different stakeholders in each stage of the design process is the key to successful design outcome. Other issues and recommendations for designers are further discussed.
\end{abstract}

Keywords Hospital Design Process, Hospital Designer, Hospital Planner, Facilities Managers, Thailand, Norway, Public Hospital

\section{Introduction}

Healthcare services, including hospitals, are considered a fundamental infrastructure of every country [1]. With the recent outbreak of the COVID-19 pandemic, the design of healthcare facilities (or healthcare architecture) has become one of the top priorities for healthcare policy makers as the design of the hospital can lead to positive patient health outcomes [2]. According to Elf et al. [3]; Ulrich et al. [4] poor healthcare architecture can often lead to adverse events, such as patient falls, disorientation, healthcare-associated infections, and patient dissatisfaction. Moreover, poor healthcare design and architecture can result in high costs to society due to complex design flaws [3] and a decrease of confidence in the healthcare system $[3,5]$.

Charise et al. [6] mentioned that the design of healthcare architecture and the design of public hospitals is an important factor that can identify the quality of modern healthcare services. A successful design process could optimize hospital services and quality [3, 7, 8]. Unfortunately, many healthcare projects including large public hospital have not based their design decisions on the systematic acquisition of knowledge between practice and research approaches. Similarly, there is still limited 
research that scrutinizes the steps of the design process that lead to successful hospital architecture (hospital facilities). The design and follow-up processes of hospital buildings are not considered as first priority of healthcare design intervention. So far, there are few studies of the hospital design process in Thailand. Thailand and Norway share similar health-care systems (universal coverage scheme). However, the two countries do not share common cultural and economic characteristics. Norway is a developed country, with related economic advantages, while Thailand as a poorer developing country is still striving to provide better healthcare services. There has not been any comparative study of hospital design process between Thailand and a Scandinavian country [8]. The lack of knowledge towards hospital design process leads to two research questions for this study. First, 'how to establish a successful hospital design process: what factors play significant roles in influencing positive design outcome in public hospitals?'. Second, what are the similarities and differences in design process of public hospitals between the Thailand and Norway? The comparison of the process in each of the countries might shed light on the answer of the two questions.

\section{Theoretical Background}

\subsection{Patient-Centered Care and Patient-Centered Architecture:}

The concept of patient-centered care has been in use since, when in 1858, Nightingale [9] identified various factors in hospital architecture that promoted health and patient safety, including air quality, temperature, light and psychological features, such as view to nature and the proximity of staff and patients [3, 9, 10]. Nightingale [9] believed that there is a direct connection between healthcare architecture and patients' health [9].

The idea that healthcare architecture can contribute to positive health outcomes changed in the mid-1990s due to the emergence of functionalist design philosophy [11]. Low-rise, decentralized hospital facilities were replaced by high-rise centralized structures [11]. The functionalist design approach had an industrialized idea of healthcare services and eliminated Nightingale [9] healing concepts. Hospital buildings turned into healing machines, where patients were often objectified due to new medical technology and treatments [3]. Patients' well-being and experiences were mostly neglected. The ideas of creating an environment that could function as a therapy in itself were ignored $[3,11]$. The industrialized design approach of healthcare architecture often leads to poor quality hospital architecture [3].

A paradigm shift in healthcare architecture and services was prompted by the rise of evidence-based design [4]. The term evidence-based design (EBD) refers to 'the deliberate attempt to base building decisions on the best available research evidence with the goal to improve outcomes and of continuing to monitor the success or failure for subsequent decision-making' [12]. This shift in healthcare services perspective has spurred a different understanding of the hospital physical environment: patients are viewed as end-users and their needs, including experiences, are one of the most important aspects in hospital services [13]. Later, the term 'healing environment', as an extension of EBD, was used to describe the hospital physical environment that has direct impact on patient psychological and health outcomes $[4,5$, 14]. Elf et al. [3]; Ulrich et al. [4] identified that hospital architecture can contribute to patients' positive health outcome including treatment reduction, and further helps to reduce stress experienced by patients and their family. Therefore, the concept of person/patient centered care is a priority for both healthcare and healthcare architecture. Clear design processes and methods that can optimize positive hospital architecture should also be identified.

\subsection{The Initial Planning and Design Phrase}

The most critical decisions in planning and design process are made in the early phase [7]. The initial phase is typically characterized as a conceptual phase in which stakeholders meet to discuss ideas and requirements that are later developed as design decisions [3]. The primary purpose of this phase is to identify the requirements of the healthcare building based on user's perspective and relate this perspective to the healthcare organization's strategic plan [3]. Co-operation among a variety of stakeholders, at this point, is crucial because knowledge can be shared and well-integrated into the architectural design [3]. The stakeholders in the initial design process consist of patient groups, healthcare staff, hospital planners, architects, engineers and facilities managers.

\subsection{User-Focused Approach in Design Process}

The concept of user-focused approach in design process and EBD is interconnected. Bate and Robert [15] described EBD as a user-focused design process with the goal of making user experience accessible to the designers, to allow them to conceive of designing experiences rather than just designing services. Thus, a user-focused approach to the design process prioritizes user needs in order to optimize the design outcome [7].

\subsection{Usability Briefing Model in Building Design Process (Healthcare Building Design Process)}

Good design is a combination of three elements (1) Functionality (2) Safety (3) Usability [16, 17] where the main objective of user-focused approach in design process is to achieve high degree of usability [8]. The term 
'usability' was introduced in the field of architecture and design to describe space management at workplaces [7]. The term was later modified to refer to the design of buildings that integrates a subjective view of users in the design process.

Munter [7] created a 'usability briefing model' with an aim to provide an easily understandable overview of the engagement over time of the different processes that can contribute to usability briefing in the building design process. The model consisted of four activities: (1) Briefing, (2) Evaluating, (3) User involvement and (4) Design. All four activities are shown in Figure 1. The Figure also provides strategies for the focus (what?), user/stakeholder (who?) and tools (how?) for the usability briefing during the various stages of the design process. Of note is the role of user input in every stage of the process.

\subsection{Cultural Aspects}

Cultural values play a role in many aspects of daily life [16]. Thailand and Norway certainly have different environmental contexts as well as social structure. Cultures can be defined as a group's shared values that become visible in action and social structure [18]. Culture and social structure consists of visible and invisible elements [16]. Hofstede et al. [18] defined six dimensions of culture (1) power distance; (2) individualism; (3) uncertainty avoidance; (4) masculinity; (5) long-term orientation and (6) indulgence. Three of these cultural dimensions have particular impact for design process of the hospital. $[8,19]$

\subsubsection{Power distance}

Thai culture manifests a high level of power distance. According to Hofstede et al. [18] Thailand is a high power distance society, where he described that the country has a high degree of centralization of authority and autocratic leadership. Therefore, the country is viewed as an hierarchical culture and inequality in society is accepted [19]. On the contrary Norway has low level of power distance [18]. The Norwegian culture values freedom and equality while control is unfavorable, communication is direct, participative, and consensus oriented.

\subsubsection{Individualism}

Thailand has low level of individualism. Thailand is known as a 'collective' culture, this refers an individual's close long-term commitment to others as members of a 'group' (a family or extended relationship) [18]. Norway has a high level of individualism, Norwegians value the individual, personal opinions, as well as the right to privacy. There are clear lines between work and private life [18].

\subsubsection{Uncertainty avoidance}

Thailand has a high level of uncertainty avoidance, which means that Thais tend to avoid uncertainty in situations: change is not acceptable in the society. Therefore, strict rules, regulations and bureaucracy are applied to minimize high level of uncertainty [19]. Meanwhile, Norway is considered as 'in between' for uncertainty avoidance, the country does not have high nor low level of uncertainty avoidance. Rules and regulations are enforced in society, however flexibility is accepted [20].

\section{Methodology}

\subsection{Design and Method Description}

This study used a qualitative descriptive design with an inductive analytic approach $[8,21,22]$. The approach was applied to transcripts of semi structured individual in-depth interviews [21].

\subsection{Setting: General Information of Two Public Hospitals}

The study focuses on the design process of university hospitals, one in each of Thailand and Norway. The Thai university hospital was established in 1972, the first building was constructed in the same year. The hospital has expanded over the years. Today, it has 1,400 beds in six medical buildings, the first of which, built in 1972, is still in use as one of the main medical buildings [8, 23].

The Norwegian university hospital was founded in 1902. In 2002, the hospital underwent major demolition but was re-built at the same location. This new construction was completed over a period of ten years. The entire hospital compound consists of 11 buildings, which includes 6 medical buildings [7]. The hospital has approximately 1,000 beds.

\subsection{Participants}

Participants for this study were experts in hospital planning who work directly in the Thai university hospital and Norwegian university hospital. Participants were involved in at least a renovation or a rebuild project of the hospital. Interviews were conducted with a total of 12 participants (7 participants from Thailand and 5 participants from Norway). Table 1 displays number and role of participants, duration of the interview and interview technique. 
Table 1. Description of Participants

\begin{tabular}{|c|c|c|c|c|}
\hline No & Interview & Roles & Duration (min) & Technique \\
\hline \multicolumn{5}{|c|}{ Thailand } \\
\hline 1 & Medical doctor & Hospital project director & 57.06 & Face-to-face \\
\hline 2 & Medical doctor & Hospital project director & 30.06 & Face-to-face \\
\hline 3 & Civil engineer & Hospital planner & 30.58 & Face-to-face \\
\hline 4 & Civil engineer & Hospital facilities manager & 60.04 & Face-to-face \\
\hline 5 & Civil engineer & Hospital facilities manager & 60.05 & Face-to-face \\
\hline 6 & Architect & Hospital planner & 84.19 & Video call \\
\hline 7 & Architect & Hospital planner & 52.48 & Video call \\
\hline \multicolumn{5}{|c|}{ Norway } \\
\hline 1 & $\begin{array}{c}\text { Senior advisor } \\
\text { (former ICU head } \\
\text { nurse) } \\
\end{array}$ & $\begin{array}{l}\text { Hospital project director, advisory and planning } \\
\text { department Sykehusbygg }\end{array}$ & 55.28 & Face-to-face \\
\hline 2 & Architect & Hospital planner & 37.56 & Face-to-face \\
\hline 3 & Medical doctor & Senior consultant/hospital planner Sykehusbygg & 51.35 & Face-to-face \\
\hline 4 & Civil engineer & Hospital facilities manager & 52.30 & Face-to-face \\
\hline 5 & Civil engineer & Hospital facilities manager & 40.05 & Face-to-face \\
\hline
\end{tabular}

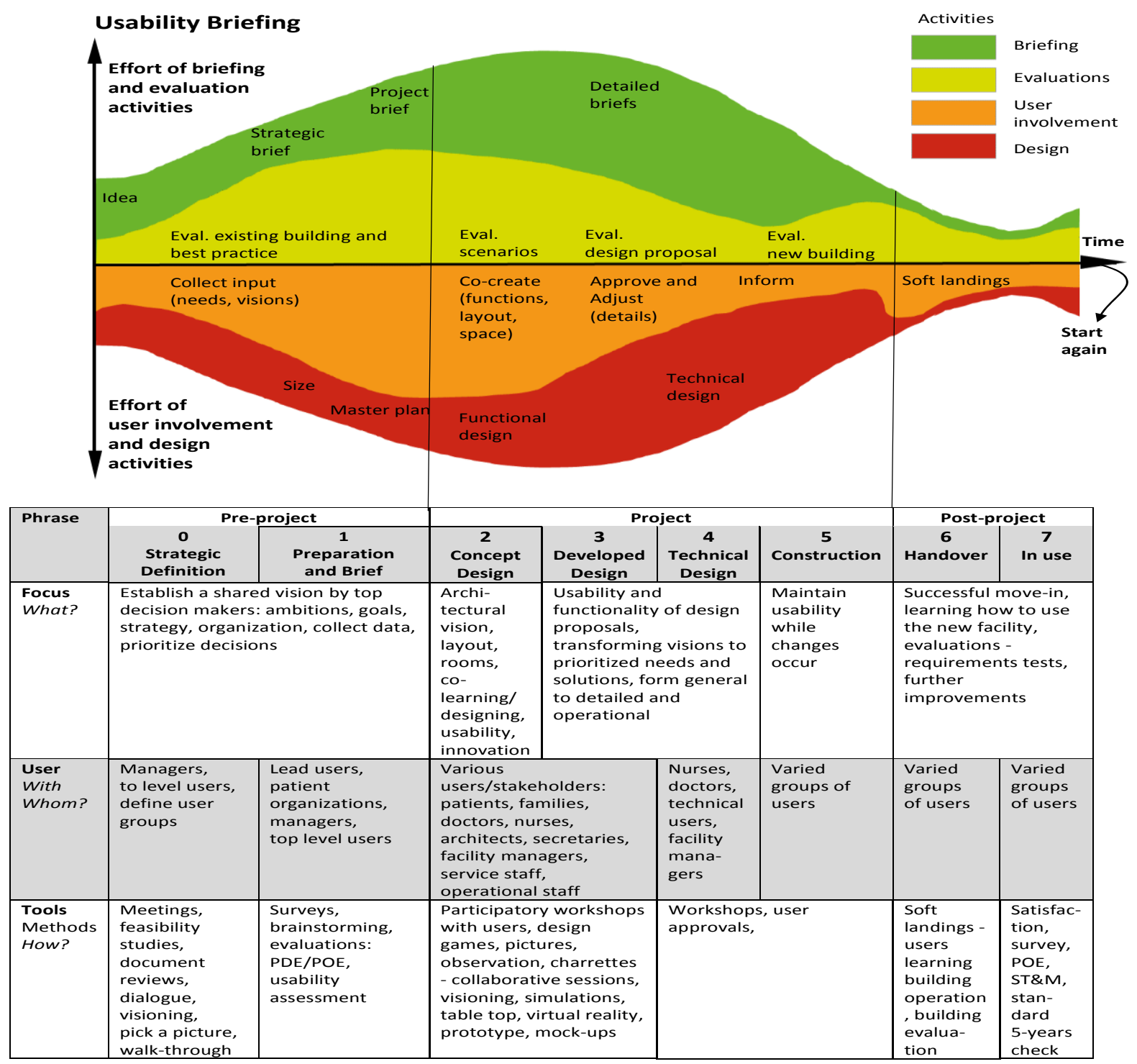

Figure 1. Usability briefing process model [7] 


\subsection{Data Collection}

Data were collected between January 2019 and August 2019 in Thailand and Norway. The interviews were carried out both face-to-face $(\mathrm{N}=10)$ and video call $(\mathrm{N}=2)$. Semi-structured in-depth interviews were conducted to obtain participants' opinion and experiences of the design process and factors that influence positive design outcome [24]. To confirm that the interview was conducted properly with reliable responses, pilot interviews were carried out in a previous study [25]. Later the interview questions were reviewed and developed aiming to answer research questions set for the study. As mentioned, this study is a qualitative study employing in-depth interview, where the aim of the study is not concerned with making generalizations to a larger population of interest [26]. In-depth interviews are conducted to create categories from data and analyze relationship between categories [26, 27].

The interviews were conducted by the first author. Initially, the purpose of the study was explained and the interview questions were given to the participants in advance. This was done to reduce the risk of preconceptions that can result in incorrect analyses [24]. The participants were advised they could withdraw from the study at any time. Interviews times ranged from 35 to 84 minutes duration. Two techniques are used to validate participant responses [28]. First, data saturation technique, where data saturation appeared after four participants of each country were interviewed. Data saturation refers to similar or same comments are provided by new participants [29]. Later 'member check technique' was used, where interview transcripts were sent to all participants to review the detailed responses and verify the interpretive accuracy and transparency [30]. Secondly, a 'peer-review technique' is utilized. In this process the interview questions are checked and developed using a pilot study. Later interview data were audited and checked by co-author of the study for the accuracy and validity of the data [28].

\subsection{Data Analysis}

A content and thematic analysis approach was employed for this study [21]. Figure 2 illustrates how the data are analyzed and developed. Data analysis can be described in six steps. First, transcription of the audio-record verbatim. Second, listening to the audio recording again and re-reading the transcripts several times to understand the context of the transcripts. Third, defining the units of meaning in the transcripts related to the research questions. Fourth, coding the units of meaning by searching for the important key phrases that indicated design process, encompassing: (1) hospital design (2) hospital planning (3) user involvement (4) other related key points. Fifth, creating relevant categories by grouping codes with related content and context. Finally, reviewing expressions and their underlying meanings to determine the emerging themes and validate whether those themes answered the research questions [21, 22, 32]. Table 2 provides an example breakdown of the data analysis.

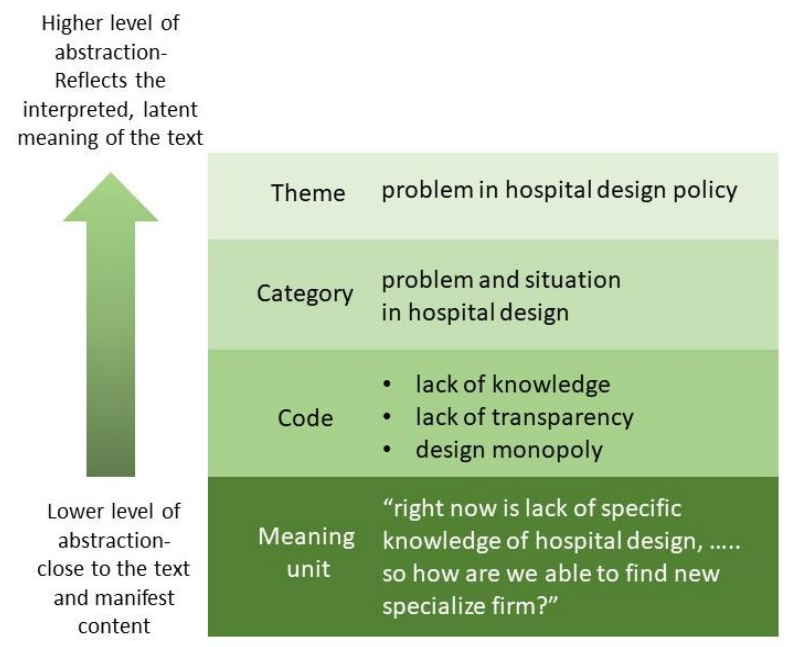

Figure 2. Example of analysis leading to higher levels of abstraction; from meaning unit to theme [31]

Table 2. Data analysis of participant responses (example)

\begin{tabular}{|c|c|c|c|c|}
\hline Participant & Unit of meaning & Code & Category & Theme \\
\hline \multirow{5}{*}{ Thai } & $\begin{array}{c}\text { Hospital designer in Thailand "right now is lack of } \\
\text { specific knowledge of hospital design, and they also } \\
\text { have to realize that hospital is a complex building. } \\
\text { Process of selecting architectural firm is also nonpublic } \\
\text { so how are we able to find new specialize firm?" }\end{array}$ & $\begin{array}{l}\text { - } \\
\text { lack of knowledge } \\
\text { lack of transparency } \\
\text { design monopoly }\end{array}$ & $\begin{array}{c}\text { problem } \\
\text { and } \\
\text { situation in } \\
\text { hospital } \\
\text { design }\end{array}$ & $\begin{array}{c}\text { hroblem in } \\
\text { hospital } \\
\text { design policy }\end{array}$ \\
\hline \multirow{5}{*}{ Norwegian } & $\begin{array}{l}\text { User involvement in hospital projects is not consistent, } \\
\text { "Some projects are very tight in terms of budget, they } \\
\text { don't want any variations to be added at all. They can } \\
\text { have patients involved in the planning but only by one } \\
\text { person or one group and in a couple of meetings". }\end{array}$ & $\begin{array}{l}\text { user involvement } \\
\text { level of user involvement } \\
\text { is varied: depends on } \\
\text { requirement of each } \\
\text { project }\end{array}$ & $\begin{array}{c}\text { current } \\
\text { hospital } \\
\text { design } \\
\text { process }\end{array}$ & $\begin{array}{c}\text { situation of } \\
\text { hospital } \\
\text { design } \\
\text { process }\end{array}$ \\
\hline
\end{tabular}




\section{Results}

Six themes emerged with ten categories, which described experiences and opinions of hospital project directors, planners and facilities managers towards hospital design brief and design process. Themes and categories are formed through content analysis of the twelve participant interview transcripts. A category is created by appraising and grouping codes that share similar meaning together. Consequently, a theme is developed grouping together two or more categories that share similar meaning. A theme expresses an underlying meaning that aims to answer research questions set for this study [31].

The six themes are (1) Healthcare system (2) Hospital management system (3) Hospital physical environment (4) Suggestion for hospital design (5) Suggestion for future hospital development, and (6) Social structure. Thailand and Norway showed similar themes; however, categories were different. The six themes are presented below. Table 3 outlines the experiences and opinions of Thai and Norwegian hospital project directors, designers and planners, and facilities managers towards the hospital design brief and design process in each category and theme. A detailed analysis of each of the themes follows below the Table 3

\subsection{Theme 1: Healthcare System, The Organization of Healthcare System, Healthcare Policy}

\section{Thailand}

Category: Lack of prioritizing healthcare system and service - Hospital project directors described the organization of Thai healthcare system as a universal coverage scheme and centralized, where large public hospitals provide primary, secondary and tertiary treatment services. Thus, patients can go directly to hospitals for consultation and are not obliged to go to a local general practitioner before attending the public hospital. Even though, there are local clinics but the clinics are not part of government healthcare and universal coverage scheme.

Thai hospital project directors added that there is a lack of prioritizing the importance of smaller, more local community hospitals as well as appropriate budget allocation for these hospitals. Although, the Thai government is aiming to improve the quality of community hospitals, the allocated budget for building and improving community hospital is still low. The community hospital is considered important for fundamental healthcare services, as the hospital can become a bulwark providing primary and secondary treatments for Thais living in rural areas.

\section{Norway}

Category: Prioritized healthcare system and service Hospital planners described the Norwegian healthcare system as based on decentralization with free choice of provider, where patients are obliged to initially consult local general practitioner (GP) in their municipality. Any subsequent specialist treatments must be referred by their GP.

The Norwegian hospital project director explained that Norwegian Health Ministry provides a special design organization called 'Sykehusbygg' (Norwegian Hospital Construction Agency) as a support unit providing consulting and research data for updating design and construction of hospitals throughout Norway.

Table 3. Response themes and categories for Thai and Norwegian stakeholders

\begin{tabular}{|c|c|c|}
\hline \multirow{2}{*}{ Theme } & \multicolumn{2}{|c|}{ Category } \\
\hline & Thailand & Norway \\
\hline $\begin{array}{l}\text { Theme 1: Healthcare system and the } \\
\text { organization of healthcare system } \\
\text { and healthcare policy }\end{array}$ & $\begin{array}{l}\text { - Lack of prioritizing healthcare system and } \\
\text { service }\end{array}$ & $\begin{array}{l}\text { - Prioritized healthcare system and } \\
\text { service }\end{array}$ \\
\hline $\begin{array}{l}\text { Theme 2: Hospital management } \\
\text { system }\end{array}$ & $\begin{array}{l}\text { - } \quad \text { Lack of organized service units } \\
\text { Problems in hospital facilities management } \\
\text { unit } \\
\text { Problem in Thai hospital Design and } \\
\text { Construction Division }\end{array}$ & $\begin{array}{l}\text { - } \quad \text { Provision of support system } \\
\text { Problems in Norwegian hospital } \\
\text { management and services }\end{array}$ \\
\hline $\begin{array}{l}\text { Theme 3: Hospital physical } \\
\text { environment }\end{array}$ & $\begin{array}{ll}\text { - } & \begin{array}{l}\text { Current state of hospital buildings and } \\
\text { master plan }\end{array}\end{array}$ & $\begin{array}{l}\text { - } \quad \text { Current state of hospital buildings } \\
\text { and master plan }\end{array}$ \\
\hline $\begin{array}{l}\text { Theme 4: Problems and current } \\
\text { situation of hospital design policy } \\
\text { and process }\end{array}$ & $\begin{array}{ll}- & \text { Problems in hospital design policy } \\
\text { - } & \text { Current situation and problems in hospital } \\
\text { design process }\end{array}$ & $\begin{array}{l}\text { - } \quad \text { Problem in hospital design policy } \\
\text { Current situation and problem in } \\
\text { hospital design process }\end{array}$ \\
\hline $\begin{array}{l}\text { Theme 5: Suggestion for hospital } \\
\text { planners, design process, FMs and } \\
\text { future development }\end{array}$ & $\begin{array}{ll}\text { - } & \text { Suggestions for hospital planners } \\
\text { - } & \text { Suggestions for hospital design process } \\
\text { Suggestions for future development of } \\
\text { hospital }\end{array}$ & $\begin{array}{ll}\text { - } & \text { Suggestions for hospital planners } \\
\text { - Suggestions for hospital design } \\
\text { process } \\
\text { Suggestions for future development } \\
\text { of hospital }\end{array}$ \\
\hline Theme 6: Social structure & - Thai mentality towards working culture & $\begin{array}{llr} & \begin{array}{l}\text { Norwegian mentality toward } \\
\text { working culture }\end{array}\end{array}$ \\
\hline
\end{tabular}




\subsection{Theme 2: Hospital Management System}

\section{Thailand}

Category: Lack of organized service units - Hospital project directors and planners commented that most of the decisions in a Thai organization are based on a 'top-down' rather than 'bottom-up' decision making process. Therefore, leaders' decisions are rarely challenged and can have a strong impact on hospital planning and development. In addition, hospital facilities managers and planers described a lack of an organized systematic work-plan within the organization. Reasons for this include the fact that there are too many contributing separate units leading to lack of communication among units, which leads to inefficient workflow, there are unorganized service and maintenance systems resulting in 'behind schedule' work progress, and finally, a lack of important data collection results in a time consuming building maintenance process.

Category: Problems in hospital facilities management unit - Thai hospital facilities managers (FMs) described two major problems within the hospital facilities management (FM) unit. First, is the lack of the understanding of the role of hospital FM unit. The hospital FMs indicated that the hospital FM unit in Thailand is a new unit and the unit has not yet developed sufficiently to encompass the core roles of FM, which focus beyond typical FM tasks (cleaning, catering, supporting services and space management). The second issue reported was a lack of opportunity and support to gain appropriate knowledge and specialist skills to be able to manage core FM services. The FM unit should have knowledge of hospital standards, hospital workflow, needs of multiple layers of users, and procedures for emergency situations in order to manage hospital core services. Hospital FM should be able to work and collaborate with all users as the center of non-medical services.

Category: Problem in Thai Hospital Design and Construction Division - a Thai government division that provides design and construction advice for Thai public hospitals, including consultation, and approval of the construction process for the hospital. Hospital planners expressed that, the division only focuses on technical and hospital standards while users' needs, including patients, are overlooked. Therefore, new design ideas as well as evidence based design (EBD) and the healing environment are usually not included in the design concept of Thai public hospitals. Hospital designers described that there is a lack of specialists (researchers, sociologists and medical planners) who can focus on user needs. The majority of employees in the division are engineers and architects.

\section{Norway}

Category: provision of support system - The Norwegian government has formed an organization (Sykehusbygg) that provides design, construction, consulting and research for public hospital design and construction. The project director of Sykehusbygg described the organization as a specialist unit that collaborates with public hospitals together with selected architectural firms to provide optimal design for Norwegian public hospitals. Sykehusbygg hospital planners added that collaborating hospitals provide data for Sykehusbygg architects and planners, who in turn use the data to amend hospital design. They mentioned that the collaboration with Sykehusbygg usually lead to positive design results as the organization has experiences with various types of government hospitals. Hospital planners of Sykehusbygg expressed that the collaboration begins with several site visits and the selection of a designer team based on content of each project as well as the amount of allocated budget.

Category: Problems in Norwegian hospital management and services - The hospital project director mentioned two problems of hospital management. First, is the lack of systematic data collection. Similar to Thai public hospitals, some of the Norwegian hospitals have been built for more than 30 years. Therefore, some data has been lost or were not stored properly in the system. Second, there is a lack of collaboration between units. The hospital planner mentioned that decisions of the leader of the hospital organization could have strong impact on the collaboration between units, hospital planning, and development. They suggested that decentralizing the organization of hospital management could have a positive impact on hospital design through collaboration between units on issues of design development.

\subsection{Theme 3: Hospital Physical Environment}

\section{Thailand}

Category: Current state of hospital buildings and master plan - All Thai respondents mentioned that current public hospital buildings are outdated, which leads to three main problems. First, poor physical and hygiene conditions due to difficulties in renovation. Hospital project directors suggested that old hospital buildings do not support new hospital standards. For example, many current clinical areas do not have access to daylight. Moreover, as the buildings are outdated it is difficult to renovate the building to a high hospital accreditation standard. Second, the buildings do not support user needs. Hospital planners expressed that hospital buildings still lack sufficient privacy and relaxation areas for patients, family and staff. Hospital FMs added that they have to deal with several day-to-day problems due to outdated hospital buildings, which hinder their focus on their primary tasks.

In terms of the hospital master plan, the hospital project directors and planners described the hospital as having an 
original master plan, but the plan has never been updated. Therefore, this out-of-date master plan leads to long-term problems. Firstly, there are difficulties when organizing logistics and work flow in the hospital. Second, there are issues in organizing zoning for long-term development and space management. Hospital FMs mentioned that the hospital is currently organizing a hospital master plan that will divide the hospital space into three zones: accommodation, research and education, and medical services. However, hospital project directors mentioned that the only option for expansion is to demolish the current buildings and construct high-rise buildings to cope with high demand for medical treatments. They added that lack of systematic data collection has had a negative impact on development of hospital master plan.

\section{Norway}

Category: Current state of hospital building and master plan - Considering the current state of hospital buildings, hospital designers expressed that the low amount of allocated budget often resulted in developments with poor functionality. However, hospital buildings are required by the Norwegian Ministry of Health and Care Services to be evaluated by Sykehusbygg specialists every year to improve the quality of health care services and the physical environment of the hospital.

Considering the hospital master plans, hospital planners mentioned that most of Norwegian public hospitals have a master plan, as it is essential for hospital development. They added that the master plan should not only cover hospital buildings but also hospital-surrounding environments, building zones, and future building ideas. Similar to Thailand, hospital planners described lack of systematic data collection as having a negative impact on development of the hospital master plan.

\subsection{Theme 4: Problems and Current Situation of Hospital Design Policy and Process}

\section{Thailand}

Category: Problems in hospital design policy - the hospital planners mentioned three problems. First, the lack of collaboration between designers and management, as mentioned above (Category: Lack of organized service system). Communication within the organization is a 'top-down' process, wherein decisions are mainly made by organization leader, which lead to lack of collaboration between stakeholders and related professions. Second, the change in hospital management team every four years leads to change in, and/or, discontinuity of hospital projects. Third, there is a significant shortfall in allocated budget for renovation and improving existing buildings. The hospital planners added that most of the budget is allocated for large new construction projects rather than the renovation of existing buildings. The hospital FMs and planners suggested that the change in management approach from top-down to collaborative and bottom-up could lead to positive development in hospital design policy as well as overall hospital management system.

Category: Current situation and problems in hospital design process - the hospital planners and FMs argued that the current situation in hospital design process does not encourage positive development of hospital building. First, there is a lack of transparency in selecting the architectural firm for the design of the hospital. Most of the architectural consultancies are dominated by one company, whose selection for a project is based on 'business connections'. The hospital planners added that architectural competition is rarely used for the selection of the design firm.

Second, there is an absence of integrating users and patient needs, including the healing environment concept, in the design process. The design of the hospital only aims to meet minimal requirements for hospital accreditation. The hospital planners expressed that hospital design should focus on the underlying issue of Thai healthcare in a demographic that has a high number of patients and high demand of medical treatments.

The current situation can lead to problems of hospital design process and policy. The lack of stakeholder collaboration can lead to a lack of specialist knowledge in term of hospital design. The hospital project directors believed that hospital design is not only the work of architects but also a collaboration between several stakeholders and users. Hospital design should be developed based on the perspective of users, especially patients. They added that medical planners are important for effective hospital design as they provide useful information and knowledge about hospital accreditation standards and can act as intermediary person between design team and users (nurses, doctors, patients). Moreover, sociologists should be involved in early stage of design process to provide useful information regarding patients and family behaviour including their needs.

\section{Norway}

Category: Problem in hospital design policy - Hospital project director and planners mentioned one problem in Norwegian design policy: lack of suitable allocated budget for hospital construction. They added that this lack of budget can lead to problems in the long-term physical environment of hospital buildings. They suggest the construction and renovation of hospital buildings is not the first priority of the Norwegian Health and Care Services. However, hospital planners suggested that if policy makers focused more on hospital construction budget it could lead to an effective hospital design project.

Category: Current situation and problem in hospital design process - The hospital planners, designers and facilities managers described the current situation of hospital design process under three aspects: the role of Sykehusbygg, user involvement, and evidence-based 
design. First, Sykehusbygg have a clear role supporting hospital planning. They provide useful information that can be used during the design process. The working relationship between Sykehusbygg and hospital is set up prior to active collaboration between the two organizations.

Second, the hospital project director described that Norwegian hospital design protocol requires involvement of different stakeholders during the design process, this includes patients and staff. Moreover, hospital planners expressed that Norwegian hospital users (staff, patients, patient family) are willing to collaborate with specialists (architects, designers, FMs) by providing comments and opinion towards the hospital design. This high collaborative design process leads to successful hospital projects that achieve Norwegian hospital standards. Hospital designers mentioned that staff involvement during design development and renovation process can minimize multiple issues that could occur during construction and operation of the hospitals.

Third, the development and implementation of evidence-based design leads to a healing environment. Insights obtained from user-involvement have impact on Norwegian hospital design. For example, Norwegian hospitals are now aiming to decentralize nurse stations thus providing more interaction between patients and nurses. Also, there are plans to increase access to greenery and nature areas by creating more hospital parks for patients, family and staff with public access.

For problems in design process, the hospital planners mentioned two problems. There is a lack of specific knowledge of hospital standards and design [a similar theme with Thai respondents] They suggested that hospital planners do not have specific knowledge and experience, especially on hospital services and patient flow, which lead to poor quality of services. Further, each hospital has a different design development goal that can often lead to misunderstanding of the design concept and hinder the development of design process.

\subsection{Theme 5: Suggestion for Hospital Planner, Design Process, FMS and Future Development}

\section{Thailand}

Category: Suggestions for hospital planners - Hospital planners and designers mentioned four aspects that they considered as important keys for effective hospital planners.

First, implementation of a study focusing on the hospital environment and patient health outcomes. The study could provide credible information for future development of hospital design. The hospital planners added that it is necessary for hospital planners and designers to observe other successful hospital projects for inspiration.

Second, ability to understand the specific environmental context of each hospital is important for hospital planners. The hospital designers expressed that a hospital should be built based on its specific environmental context. Hospital planners added that some architects reuse the same architectural plans for hospitals located in different environmental and social contexts.

Third, implementation of systematic data collection and specific knowledge, where data focus on hospital standards, hospital workflow and patient needs. For example, it is helpful to have a record of patient flow and patient profiles. In addition, specific knowledge provided by hospital planners for renovating and evaluating hospital buildings. Hospital planners described that these data can be used to improve hospital development and design.

Lastly, congruence between user needs and hospital standards. Hospital project directors, planners and FMs agreed that it is necessary to strike a balance between users' needs and hospital standards.

Category: Suggestions for hospital design process Two major aspects were suggested by hospital project directors, planners and FMs.

Firstly, regarding hospital design standards and design guidelines. Hospital planners suggested that hospital standards are the first priority for hospital construction and renovation. They added that four components; hygiene, ventilation, patient and treatment flow, and infection control are the most significant aspects of hospital standards. Implementation of clear guidelines for hospital design standards where observation, interview, patient needs, and patient profiles are essential components. As well as hospital design standards, the concept of healing environment is becoming more important in hospital design process. Hospital designers mentioned that utilizing evidence based design and healing environment approaches can have a positive impact on patient health outcomes. However, the guidelines require regular updating for effectiveness.

Second, is the importance of user involvement in the design process. Hospital planners recommended that user-involvement is the first concern of hospital design process, where patients are the focus of hospital design. Encouraging collaboration between stakeholders; architect, system engineer, FMs, patients, staff and related professions is essential. However, guidelines for user-involvement that clearly specify the role of each stakeholder should be established. Moreover, user involvement should be implemented at the early stage of design process leading to effective building operations and better quality of healthcare service. Hospital FMs and planners emphasized that architects and designers should not be the main decision makers in design process.

Category: Suggestions for future development of hospital - Hospital project directors and planners suggested that the capacity to efficiently develop a hospital building for the future was important. They 
indicated that hospital buildings can be categorized for renovation or construction based on building's age. Old buildings can be renovated with the aim of reaching minimum hospital standards, whereas new buildings can be constructed to reach a higher standard. Hospital planners added that building evaluation should be done regularly by specialists. Further, the hospital project directors, planners and FMs mentioned the importance and implementation of IT services, which can be utilized for improving hospital services, including; hospital standards, space management, future strategic planning for the hospital, patient services. Lastly, hospital project directors, planners and FMs addressed the adaptation of hospital services for future healthcare development. They added that healthcare service is changing direction from treatment-based to a costumer-based service. For example, hospitals are aiming to provide better services for elderly patients in terms of their broad-based needs as well as specific medical treatments. They added that hospital design should integrate international standards, patient needs, and safety considerations for patients and staff.

\section{Norway}

Category: Suggestion for hospital planners - Three aspects were mentioned by hospital planners and designers. First, the importance of a hospital master plan. The hospital planners and designers suggested that the hospital master plan is the crux of hospital buildings development. They added that a master plan is a major part of hospital designing and planning. A well-designed master plan leads to long-term success of hospital projects and high quality services. One of hospital planners expressed that updating the hospital master plan is not the first priority of hospital policy makers. However, hospital planners recommended that the master plan should be evaluated every two to four years and a long term master plan should be planned for minimum of 20 to 30 years.

Second, implementation of systematic data collection through user-involvement. Sykehusbygg hospital project director and planners suggested that user experience data collected through observation, surveys, focus-groups, and interviews would provide valuable insights and should be integrated into a hospital data based for future use. They added that this user data could also be used for hospital design guidelines. Knowledge obtained from case studies and research projects should be developed and used for future hospital design. Hospital FMs argued that specific knowledge for hospital design, mostly based on several site visits, observation, insight obtained from users, and hospital planners own experiences was important.

Category: Suggestion for hospital design process Hospital planners and designers described two topics that lead to successful design process.

First, prioritizing hospital design guideline. Similar to Thailand, Norwegian hospital planners described that hospital standards and regulations are the most important aspects that hospital planners and designers should consider before development of the design concept. They added that there are four components of hospital design standards, namely: function, hygiene, ventilation, logistics, and infection control. They mentioned that a successful project depends on the integration of hospital design guidelines and the involvement of different stakeholders during design process.

Second, the implementation of IT service in hospital design. The hospital project director and planners suggested that IT service is useful for communication during design process and data collection. They described that Norwegian hospitals have started using IT services to collect patient data for hospital design development.

Category: Suggestion for future development of hospital - Two aspects were mentioned by hospital project director, planners, designers and FMs. First, the need to improve the integration of evidence based design and healing environment. They added that many successful hospital projects focused on patient-centered and healing environment approach. Therefore, it is necessary to promote the use of these two approaches in further design work. Second, consideration of hospital expansion as mentioned in hospital design process. The Norwegian hospital planners were concerned about the higher demand of healthcare services in the future, they stressed that hospital buildings should be flexible and adaptable for future expansion.

\subsection{Theme 6: Social Structure}

\section{Thailand}

Category: Thai mentality towards working culture Hospital planners and FMs mentioned that Thai culture also plays a role in the hospital design process. There is considerable internal and government bureaucratic influence in the provision of large infrastructure developments. Hospital FMs expressed that urgent building problems always take an extremely long time before being tackled, which leads to complications.

Second, a strong hierarchy and large social gap in Thai society also affects an organization's culture and influences hospital design policy and process. A strong social and organizational hierarchy, as well as collective culture, has impact among employees, which can lead to a lack of cross unit communication, collaboration and teamwork. High level manager's or director's decisions are usually held as unassailable, which results in a 'top-down' management mentality. Hospital FMs mentioned that user involvement approach is useful but it is not effective due to this 'top-down' work mentality.

\section{Norway}

Category: Norwegian mentality toward working culture - Hospital planners and FMs described two cultural 
aspects that influence working culture including hospital design process. First, high collaboration approach, where teamwork is considered important for successful design project. Therefore, most of hospital projects involve the opinions and suggestion from users (patients and staff) and different stakeholders which includes hospital planner, designers, FMs, project managers and engineers.

Second, like other Scandinavian cultures, Norwegian culture has a flat hierarchical structure, where Norwegians respect each individual's freedom and equality. This cultural value has impact on Norwegian working culture, where decisions are made by the broader design team working on a project rather than decisions coming from top manager or policy makers.

\section{Discussion}

The aim of this study was to address two important questions regarding hospital design process: how to establish a successful design process, and what factors play significant roles in influencing positive design outcomes for a public hospital. Opinions of those involved directly in the process: project directors, planners, and facility managers, were elicited. Comparisons were made between design processes in Norway (a developed economy) and Thailand (as a developing economic entity).

First, we discussed the main findings of the data analysis and then further addressed and discussed each of the emergent themes in turn.

The main findings primarily revealed differences in the way Thailand and Norway handle and manage the design process of public hospitals. Both Thailand and Norway governments provide assistance through state-sponsored organizations to support the design of public hospitals. However, the Thai organization (Design and Construction Organization) focuses on the technical aspects of hospital construction and hospital standards. User needs and involvement in the design process of the hospital are not included as priorities in the design process. On the other hand, the Norwegian government organization (Sykehusbygg) provides hospital design specialists and researchers, which work closely with hospital staff during the design process. The findings indicated that Sykehusbygg staff working together with hospital employees can lead to a successful design project. The collaboration between Sykehusbygg and the hospital is indicative of the usability briefing model in building design process [7, 33]. The model (concept design to construction) emphasizes the involvement of various stakeholders including hospital staff, architects, planners, service staff and facilities managers leading to a successful design brief. The emergent themes from this broad overview of the data are further discussed below.

\section{Theme 1: Healthcare System, The organization of Healthcare System, Healthcare Policy}

Another factor that can influence the design process of the hospital is the national healthcare system. Hospital project planners from Thailand and Norway mentioned that prioritizing the establishment of high quality community hospitals, which focus on smaller groups of users, as opposed to larger user group major public hospitals, can lead to better design outcomes for hospitals. Study participants from both Thailand and Norway agreed that sufficient budget should be allocated to hospital projects in order to achieve a high standard facility. This outcome is supported by research showing the healthcare system can have a direct impact on Thai public hospital design [8].

\section{Theme 2: Hospital Management System}

The results also indicate that hospital management systems can also influence the design process of hospitals. For Thailand, the lack of an organized supporting service system hinders any positive design process. Facility managers and planners reported the lack of an organized systematic work-plan within the organization. Problems result from (1) too many separate and non-communicative units (2) unorganized service and maintenance systems and (3) limited focus on data collection. These three problems lead to a general lack of communication, are unnecessarily time consuming, and slow the progress of design work. For Norway, similar to Thailand, the lack of system data collection was also addressed by hospital project directors. For example, where data were not collected or stored effectively, subsequent data retrieval and data loss present problems when designing renovation or future expansion plans for the hospital. Norwegian hospital planners in the study also expressed the feeling that decisions by hospital leaders can have a strong impact on collaboration between units. They suggested that decentralization within hospital management organization would lead to more collaboration between stakeholders and design teams. According to Elf et al. [3] two major factors that ensure a high quality healthcare environment are the use of documentation and collaboration for shared decision making. The use of documentation refers to design decisions that are conveyed through documents (design proposals, program, and or/brief) developed in planning and design stages. These documents are necessary for decision-making in a building process [3]. Collaboration for shared decision refers to fostering ownership of and participation in design decision by healthcare planners and users or known as 'co-creation' design process [3, 34].

Our findings also revealed problems in hospital facilities management in Thailand. Hospital FMs described that the FM unit is relatively new and has yet to be involved in more serious FM core practices: hospital standards, a complex and diverse mix of users, and 
serious/emergency events. Moreover, Thai FMs suggested that the lack of knowledge concerning hospital FM inhibits the opportunity for FMs and hospital service units to collaborate and improve the service design of the hospital. On the contrary, Norwegian FMs did not express any problems within the unit. Similar findings were reported by Boge and Aliaj [35] who found that FM in Norwegian hospitals is recognized as one of the most robust hospital service units in European hospitals. The Thai hospital support service division is currently a far less-developed service provider than the Norwegian hospital FM's division.

\section{Theme 3: Hospital Physical Environment}

The current state of a hospital building is also an important factor influencing the design process. Thai hospital project directors, planners and FMs reported that a hospital building that is outdated has led to three problems (1) poor physical and hygiene conditions (2) hospital buildings that do not support user needs, and (3) the prevalence of minor day-to-day maintenance problems. Norwegian hospital project directors, planners and FMs addressed the lack of budget allocation for maintaining and renovating hospital buildings as their main issue. However, they commented that Norwegian hospital buildings are obliged to undergo annual evaluation. Healthcare environment research has shown that building evaluations are a prerequisite for successful and continuous quality improvement of the planning and design process and of the healthcare architecture [36]. Our findings also indicated that Thai hospitals are not being evaluated regularly and buildings are outdated which has led to physical environment problems. Both Thailand and Norwegian hospital project directors, planners and FMs value the establishment and regular update of a hospital master plan, as it is the key to successful future development and can be part of a positive hospital design process.

\section{Theme 4: Problems and Current Situation of Hospital Design Policy and Process}

The findings of our study indicated that Thailand has more problems in hospital design policy than Norway. For Thailand, three major problems were mentioned (1) lack of collaboration between user and stakeholder, in fact, the most important decisions usually come from an organization leader or 'top-down' decisions (2) frequent change in hospital management teams (3) lack of allocated budget for hospital building. The lack of collaboration between users and stakeholders was mentioned throughout the study, wherein hospital project directors, planners and FMs emphasized that changing management strategy from top-down to a collaborative approach may lead to a more positive hospital design policy. This is consistent with research focusing on co-creation activities, where collaborative design process between designers and users is integrated throughout the design process [7]. On the other hand, Norwegian planners were mainly concerned about a single problem: lack of allocated budget sufficient for a successful project.

Our findings also showed differences in current situation and problems in hospital design process between Thailand and Norway. Thailand has several problems regarding hospital design process. The initial quality of the design process is compromised by (1) lack of transparency in selecting an architectural firm, and (2) lack of integrating users and patient needs, including the healing environment concept, in the design process. The hospital planners and FMs reported that these two problems stemmed from two reasons (1) the lack of understanding of collaboration between stakeholder and users (2) the lack of knowledge in terms of hospital design. Based on our study, Thailand has a serious lack of understanding of user involvement, as this factor was repeatedly mentioned by hospital project directors, planners and FMs throughout the study. For Thailand, user involvement or user's need assessment, has rarely been set as first priority for design process. That said, Thai hospital project directors commonly expressed that hospital design should be developed based on the perspective of users, especially patients. Results of our study also revealed that hospital planners and sociologist should be involved in early stage of design process. A similar position was discussed by Prugsiganont and Jensen [8]; Waroonkun [36] with regard to hospital space management. These studies suggest that Thai hospitals currently experience major problems with space management. Hospital spaces are overwhelmed by high patient numbers and hospital designers must focus on managing patient 'workflow' as well as patient needs, and a positive healthcare environment.

On the contrary, Norwegian hospital planners, designers and FMs expressed positive opinions towards current situation of hospital design process. They reported (1) clear collaborative roles of Sykehusbygg and the hospital in design process. (2) implementation of user involvement, as well as the involvement of different stakeholder, in each stage of the design process and (3) development and implementation of an evidence-based design (EBD) approach. This study strongly identified user involvement as the unrivalled factor leading to successful design process. The clear collaboration between Sykehusbygg and the implementation of EBD is also supported by several studies indicating that these are methods of ensuring a quality healthcare environment $[3$, 14].

\section{Theme 5: Suggestion for hospital planner, Design process, FMS and Future development}

Results of this study provide a basis for suggestions to hospital planners, project directors and, FMs regarding the design process and future development. For Thailand, the 
suggestions given by study participants are based on problems and current situation among hospital design teams. Four strategies are suggested: (1) implement research focusing on the hospital environment and patient health outcome, this is consistent with the implementation of an EBD approach [14, 37]. (2) Understand the specific environmental context of each hospital, by focusing on usability where quality design depends on subjective view of user context, culture, situation and experiences [7, 37]. (3) Implement systematic data collection, where data are focused on hospital standards, hospital workflow, and patient needs [38]. Data collected about patients' and employees' points of view and information should be stored and available for future use in designing healthcare spaces. (4) Explore congruence between user needs and hospital standards in order that hospital design focuses on both patients' needs and hospital standards.

For the Norwegian hospital planners and designers, participants emphasized the importance of a hospital master plan. They added that a master plan is the core of future development of hospital buildings. Similar to Thailand, the Norwegian hospital design team expressed the implementation of systematic data collection through user-involvement as a key to successful design process.

In terms of hospital design process, both Thai and Norwegian hospital planners mentioned the importance of hospital design standards and design guidelines these include; hygiene, ventilation, patient workflow, and infection control. These four components are the most important that hospital designers should consider during the design process. Ulrich et al. [4]; Patterson et al. [32] found that hospital standards are one of the more important elements that can improve patient experience during hospitalization. These results, also stressed that both countries see the importance of implementation of user involvement in design process; Thai and Norwegian designers agreed that user involvement should be implemented in the early stage and throughout the design process. The Norwegian respondents added that the implementation of IT services as communication tools and data collection is essential.

For the future development of hospitals in Thailand, hospital planners and project directors suggested categorizing hospital buildings as suitable for short-term and long-term renovation. Old buildings where the condition is substantially deteriorated should be renovated to meet minimum hospital standards. They also suggested regular building evaluations be conducted by specialists.

For Norway, the hospital project directors, planners and FMs suggested more integration of evidence-based design during design process, more patients' opinions as well as employee involvement should be included. Both country's respondents agreed that hospital service is changing direction towards a 'customer-focus' and that there is a higher demand of healthcare services. Therefore, hospital buildings should prepare for expansion and provide for flexibility. Our findings support research on healthcare surge capacity, which refers to the ability of healthcare facilities to treat the increased number of patients, especially in public health services [8].

\section{Theme 6: Social structure}

The final factor considered to influence the design process is the social structure of the communities served by the hospital; both country's design team mentioned the influence of work culture mentality. Thailand is known as highly bureaucratic country with a hierarchical culture; a top-down decision approach is often employed for design decisions and process. However, the Thai hospital planners and FMs expressed that top-down decision inhibited the development and progress of an effective design process. For Norway, the hospital planners and FMs reported a highly collaborative approach wherein teamwork was seen as an important approach during the design process. In addition, Norway has a flat hierarchical culture, Norwegians value individual freedom and equality. Therefore, teamwork, collaboration and integration of medical staff and patient opinions are seen as normal in Norwegian work culture. These findings indicate that social structure is a factor that can have significant influence on the design process $[8,18,19]$.

\section{Limitations and Suggestions for Future Work}

The sample in this study was small $(\mathrm{n}=12)$ and from only two public hospitals. As this study is qualitative research, it is typical to have small sample sizes in which the focus is on richness and answering research questions rather than making generalizations. Such a small sample size could limit the transferability of the findings to other hospital design contexts. Furthermore, the participants may not be representative of all project directors, planners, and facility managers. The study participants only represent the experiences, opinions and perceptions of the employees at Maharaj and St Olav's hospitals. Findings provide insights about factors that can optimal hospital design. However, further exploration of this topic should be conducted (e.g. hospital design process, user-involvement) and should include a larger sample of participants from several public hospitals.

\section{Conclusions}

To establish a successful design process, many elements come into play, one of the most important factors that leads to optimal design outcome is user involvement in early stage of design process. Moreover, the involvement of different stakeholders should be integrated during different stages of the design process. 
This study highlighted that user's (patient, medical staff, service staff etc.) perspective is the key to successful design. In addition, there are several other factors that can influence optimal healthcare design. Firstly, hospital management systems must involve collaboration between government-owned construction agencies and the hospital during the design process, they should facilitate systematic data collection, encourage collaboration and communication between hospital units. Second, the current state of the physical environment (hospital buildings) can influence the expansion or renovation process. Third, the way each hospital design team organizes its design process is important; specifically the more collaboration between units and involvement of users the more successful of hospital project. Fourth, social structure that has impact on the organization of work culture including the organization of design team must be taken into account. For example, Thailand is a bureaucratic and hierarchical culture whereas, Norway, on the other hand has a rather flat hierarchical culture. Therefore, collaboration is encouraged among the Norwegian work culture more so than Thais. Both Thai and Norwegian participants stressed the importance of amending the design process to include more integration of EBD, regular building evaluation, involvement of hospital design expert/specialist, and the update of a master plan.

Thailand is still a developing country that strives to provide sufficient healthcare services while Norway is a country that provides fully government subsidized healthcare services. However, Thailand can learn from Norway regarding the concept of early involvement of stakeholders in the design process. The involvement of users and experts in the different stages of the design process can lead to positive results in hospital physical environment that suits the diverse needs of hospital users.

\section{Contribution to Knowledge and Practice}

- This study compares Thai and Norwegian healthcare systems and design process, findings from this study have can be applied as guideline for future studies that compare two hospitals in different contexts.

- During the design process, user involvement is the most important aspect leading to successful hospital project outcome. Different users/stakeholder and specialists should be involved in different stages of the design process.

- Clear collaboration between design units and teams should be established in the early stages of the design process - communication between each unit should be conducted regularly through short but effective meetings. The role of each design unit should be clearly specified.
Clear design processes and plans should be established to include (1) strategic planning (2) preparation of a design brief (3) concept design, developed design, technical design and construction (4) hand over, in-use (building evaluation, updating hospital master plan) [7].

\section{REFERENCES}

[1] D. Amos, C. P. Au-Yong, and Z. N. Musa, "Enhancing The Role of Facilities Management in The Fight Against The COVID-19 (SARS-CoV-2) Pandemic in Developing Countries' Public Hospitals," Journal of Facilities Management, Vol. 19, No. 1, pp. 22-31, 2020. DOI: 10.1108/JFM-06-2020-0034

[2] J. West, "Design in Healthcare: The Challenge of Translation," Design for Health, Vol. 4, No. 2, pp. 252-263, 2020. DOI: $10.1080 / 24735132.2020 .1783880$

[3] M. Elf, P. Frost, G. Lindahl, and H. Wijk, "Shared Decision Making in Designing New Healthcare Environments Time to Begin Improving Quality," BMC Health Services Research, Vol. 15, No. 114, pp. 1-7, 2015. DOI: $10.1186 / \mathrm{s} 12913-015-0782-7$

[4] R. Ulrich, C. Zimring, X. Quan, A. Joseph, and R. Choudhary, "III: Reduce Stress and Improve Outcomes and IV: Improve Overall Healthcare Quality," in The Role of the Physical Environment in the Hospital of the 21st Century, The Center for Health Design, 2004, pp. 15-24, pp. 25-27

[5] E. R. C. M. Huisman, E. Morales, J. V. Hoof, and H. S. M. Kort, "Healing Environment: A Review of the Impact of Physical Environmental Factors on Users," Building and Environment, Vol. 58, pp. 70-80, 2012. DOI: 10.1016/j.buildenv.2012.06.016

[6] A. Charise, H. Wittle, S. Whyte, E. J. Sutton, J. L. Bender, M. Massimi, L. Stephens, J. Evans, C. Logie, R. M. Mirza, and M. Elf, "Questioning Context: A Set of Interdisciplinary Questions for Investigating Contextual Factors Affecting Health Decision-Making," Health Expect, Vol. 14, No. 2, pp. 115-132, 2011. DOI: 10.1111/j.1369-7625.2010.00618.x.

[7] A. F. Munter, "Usability Briefing for Hospital Design: Exploring User Needs and Experiences to Improve Complex Buildings," PhD thesis, pp. 97-115, 2016, Technical University of Denmark.

[8] S. Prugsiganont, and P. A. Jensen, "Identification of Space Management Problems in Public Hospitals: The Case of Maharaj Chiang Mai Hospital," Facilities, Vol. 37, No. (7/8), pp. 435-454, 2019. DOI: 10.1186/s40064-016-3665-4.10.11 08/F-01-2018-0001.

[9] F. Nightingale, "The Cause of Disaster at Scutari Hospital," in Notes on Matters Affecting the Health, Efficiency and Hospital Administration of the British Army, Harrison \& Sons, 1858, pp. 81-139

[10] M. Browall, I. Koinberg, H. Falk, and H. Wijk, "Patients' Experience of Important Factors in The Healthcare Environment in Oncology Care," International Journal of Qualitative Studies on Health and Well-being, Vol. 8, No. 1, 
pp. 1-10, 2013. DOI: 10.3402/qhw.v8i0.20870.

[11] J. Kisacky, "Chapter 1: Hospital building as Means of Disease Prevention, 1700-1873, and Chapter 4: Hygienic Decentralization vs. Functional Centralization: Reasons for Continuity and Change, 1898-1917," in Rise of The Modern Hospital (An Architecture History of Health and Healing 1870-1940), $1^{\text {st }}$ ed, University of Pittsburg Press, 2017, pp. 12-77, 166-234

[12] J. Malkin, "Evidence-Based Design," in A Visual Reference to Evidence-Based Design, The Center for Health Design, 2008, pp. 2-18

[13] C. C. Andrade, A. S. Devlin, C. R. Pereira, and M. L. Lima, "Do the Hospital Rooms Make A Difference for Patients' Stress? A Multilevel Analysis of the Role of Perceived Control, Positive Distraction, and Social Support," Journal of Environmental Psychology, Vol. 53, pp. 63-72, 2017. DOI: 10.1016/j.jenvp.2017.06.008

[14] D. K. Hamilton, "Four Levels of Evidence-Based Practice," Healthcare Design, Vol. 3, No. 4, pp. 18-26, 2003. DOI: 10.1108/F-07-2016-0079

[15] P. Bate, and G. Robert, "Experience-Based Design: From Redesigning The System Around The Patient To Co-Designing Services With The Patient," Quality and Safety in Health Care, Vol. 15, No. 1, pp. 307-310, 2006. DOI: $10.1016 /$ j.buildenv.2012.06.016

[16] J. S. Baek, S. Kim, and T. Harimoto, "The Effect of Cultural Differences on a Distant Collaboration for Social Innovation: A Case Study of Designing for Precision Farming in Myanmar and South Korea," Design and Culture, Vol. 11, No. 1, pp. 37-58, 2019. DOI: 10.1080/17547075.2019.1565 400

[17] T. J. M. V. D. Voordt, and H. B. R. V. Wegen, "Chapter 6: Quality assessment methods of measurement," in Architecture in Use: An Introduction to The Programming Design and Evaluation of Buildings, $1^{\text {st }}$ ed, Elsevier, 2010, pp. 169-219

[18] G. Hofstede, G. J. Hofstede, and M. Minkov, "Part II: Dimension of National Cultures," in Cultures and Organizations: Software of The Mind, $1^{\text {st }}$ ed, McGraw-Hill, 2010, pp. 53-296

[19] C. Riratanaphong, "Performance Measurement of Workplace Change - In Two Different Cultural Contexts," PhD thesis, pp. 109-125, 2014, TU Delft, The Netherlands.

[20] F. Dobbin, and T. Boychuk, "National Employment Systems and Job Autonomy: Why Job Autonomy Is High in the Nordic Countries and Low in the United States, Canada, and Australia," Organizational Studies, Vol. 20, No. 2, pp. 257-291, 1999. DOI: 10.1177/0170840699202004

[21] A. Anaker, L. V. Koch, A. Heylighen, and M. Elf, "It's Lonely": Patients' Experiences of the Physical Environment at a Newly Built Stroke Unit," Health Environments Research and Design Journal, Vol. 12, No. 3, pp. 141-152, 2019. DOI: $10.1177 / 1937586718806696$

[22] S. Elo, and H. Kyngas, "The Qualitative Content Analysis Process," Journal of Advanced Nursing, Vol. 62, No. 1, pp. 107-115, 2008. DOI: 10.1111/j.1365-2648.2007.04569.x

[23] Maharaj Chiang Mai Hospital, "History of Suan Dok (the
Maharaj Nakorn Chiang Mai Hospital) Faculty of Medicine, Chiang Mai University, Thailand," http://web.med.cmu.ac.t h/index.php/th/main-aboutus/med-cmu-history. (Accessed Dec. 1, 2020).

[24] V. Braun, and V. Clarke, "What Can "Thematic Analysis" Offer Health and Wellbeing Researchers?" International Journal of Qualitative Studies on Health and Well-Being, Vol. 9, No. 1, pp. 1-2, 2014. DOI: 10.3402/qhw.v9.26152

[25] J. W. Creswell and C. N. Poth, "Five Qualitative Approaches to Inquiry," in Qualitative Inquiry and Research Design: Choosing Among Five Approaches, $4^{\text {th }}$ ed, SAGE, 2018, pp. 65-110

[26] K. Charmaz, "Grounded Theory: Methodology and Theory Construction," International Encyclopedia of the Social \& Behavioral Science, $2^{\text {rd }}$ ed, Elsevier, 2015, pp. 402-407

[27] S. L. Dworkin, "Sample Size Policy for Qualitative Studies Using In-Depth Interview," Archives of Sexual Behavior, Vol. 41, pp.1319-1320, 2012. DOI: 10.1007/s10508-012-00 16-6

[28] L. Leung, "Validity, Reliability, and Generalizability in Qualitative Research," Journal of Family Medicine and Primary Care, Vol. 4, No. 3, pp. 324-327, 2015. DOI: 10.4103/2249-4863.161306

[29] B. Saunders, J. Sim, T. Kingstone, S. Baker, J. Waterfield, B. Bartlam, H. Burroughs, and C. Jinks, "Saturation in Qualitative Research: Exploring Its Conceptualization and Operationalization," Quality \& Quantity, Vol. 52, No. 4, pp. 1893-1907, 2018. DOI: 10.1007/s11135-017-0574-8

[30] L. Harvey, "Beyond Member-Checking: A Dialogic Approach to The Research Interview," International Journal of Research \& Method in Education, Vol. 38, No. 1, pp. 23-38, 2015. DOI: 10.1080/1743727X.2014.914487

[31]C. Erlingsson and P. Brysiewicz, "A Hands-On Guide to Doing Content Analysis," African Journal of Emergency Medicine, Vol. 7, No. 3, pp. 93-99, 2017. DOI: 10.1016/j.afjem.2017.08.001

[32] E. S. Patterson, E. B. N. Sanders, C. M. Sommerich, S. A. Lavender, J. Li, and K. D. Evans, "Meeting Patient Expectations During Hospitalization: A Grounded Theoretical Analysis of Patient-Centered Room Elements," Health Environments Research and Design Journal, Vol. 10, No. 5, pp. 95-110, 2017. DOI: 10.1177/1937586717696700

[33]A. Blyth, and J. Worthington, "Briefing explained: Articulating the briefing process," in Managing The Brief for Better Design, $1^{\text {st }}$ ed, Routledge, 2010, pp. 13

[34] G. Lindahl, and N. Ryd, "Clients' Goals and The Construction Project Management Process," Facilities, Vol. 25, No. 3/4, pp. 147-156, 2007. DOI: 10.1108/02632770710 729737

[35] K. Boge, and A. Aliaj, "Albania vs Norway - FM at Two University Hospitals," Facilities, Vol. 35, No. 7/8, pp. 462-484, 2007. DOI: 10.1108/F-07-2016-0079

[36] T. Waroonkun, "A Structural Format to Facilitate User Input for The Co-Design of A Cardiac Health Unit," Civil Engineering and Architecture, Vol. 8, No. 5, pp. 760-770, 2020. DOI: $10.13189 /$ cea.2020.080503

[37] I. Bulakh, O. Chala, V. Divak, "Dynamics of Architectural 
and Urban Planning Hospital Systems Evolution," Civil Engineering and Architecture, Vol. 8, No. 4, pp. 586 - 598, 2020. DOI: $10.13189 /$ cea.2020.080423.
[38] W. M Novicoff, "Data-Driven Performance Improvement in Designing Healthcare Spaces," Health Environments Research and Design Journal, Vol. 7, No. 1, pp. 79-84, 2013. DOI: $10.1177 / 193758671300700107$ 